\section{Lymphangiomatosis presenting with bronchial cast formation}

\author{
Laurence G Nair, Caroline P Kurtz
}

\begin{abstract}
Lymphangiomatosis is a rare disorder of the lymphatic system that is known to cause chylothorax. Chyloptysis may occur but chylous bronchial cast formation is rare. A case is reported of lymphangiomatosis in a 34 year old woman whose initial manifestation was cough productive of bronchial casts. Two years later the patient developed a chylothorax. Ligation of the thoracic duct through a low thoracotomy was curative.

(Thorax 1996;51:765-766)
\end{abstract}

Keywords: lymphangiomatosis, lymphangiectasis, chyloptysis, bronchial casts.

Department of Critical Care

Medicine, Norwalk Hospital, Norwalk, Connecticut 06850, USA

L G Nair

C P Kurtz

Correspondence to: Dr L Nair.

Received 30 August 1994 Returned to authors 16 November 1994 Revised version received 26 May 1995 Accepted for publication 20 July 1995

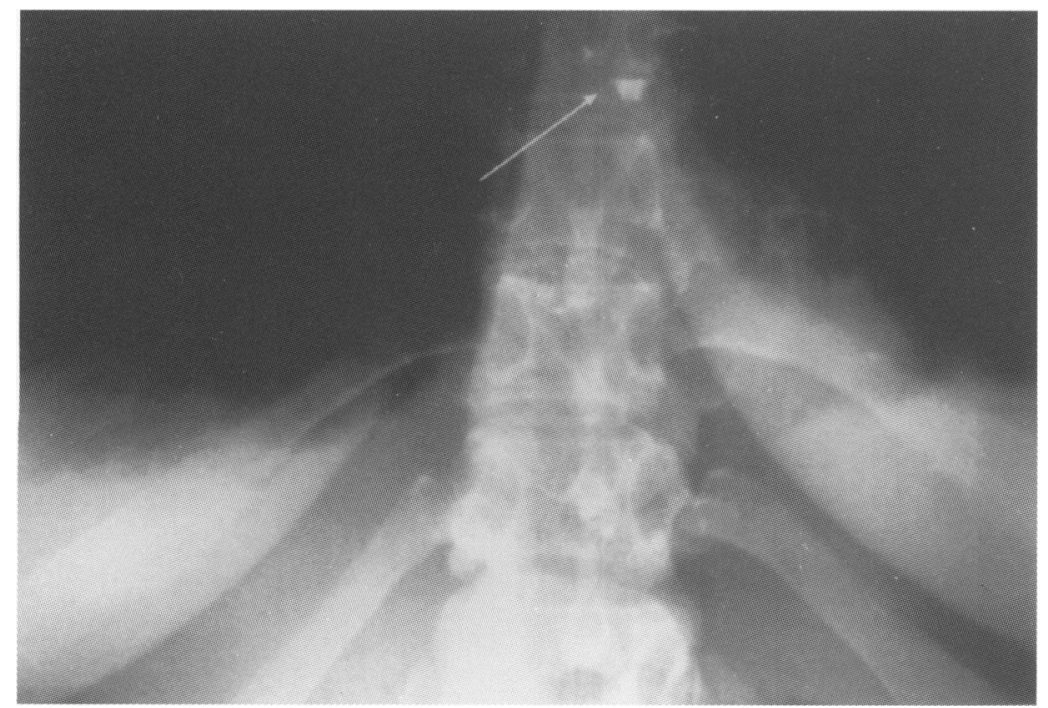

Figure 1 Lymphangiogram showing fluidlfuid levels (arrow) in the mediastinum. the middle and lower lung fields. Pulmonary function tests revealed a forced expiratory volume in one second $\left(\mathrm{FEV}_{1}\right)$ of 2.21 (71\% predicted), forced vital capacity (FVC) of $2 \cdot 751$ ( $71 \%$ predicted), $\mathrm{FEV}_{1} / \mathrm{FVC}$ of $80 \%$, total lung capacity (TLC) of 4.3 ( $77 \%$ predicted), and a transfer factor of $17 \cdot 2 \mathrm{mmol} / \mathrm{min} / \mathrm{kPa}(78 \%$ predicted). Sputum culture grew normal flora. A computed tomographic (CT) scan of the thorax revealed mucous impacted in the bronchi. Defects in the liver and spleen were seen consistent with cysts or haemangiomas. There was no evidence of bronchiectasis. Sweat chloride levels and quantitative immunoglobulins including IgE were normal. Aspergillus skin test was positive but aspergillus precipitins were negative.

The patient underwent fibreoptic bronchoscopy in February 1991. Many casts were aspirated that floated in normal saline which, on microscopic examination, were found to be composed of mucin, scattered inflammatory cells, and macrophages. Cultures and bronchial biopsy samples were unrevealing. A diagnosis of plastic bronchitis ${ }^{1}$ was made and treatment with bronchodilators, mucolytics, intermittent corticosteroids, and antibiotics was instituted. Nonetheless, over the next 18 months, episodic dyspnoea, wheezing, and cough productive of bronchial casts continued.

In August 1992 she presented with three days of shortness of breath and a respiratory rate of 40 breaths per minute. Chest examination revealed dullness to percussion bilaterally with decreased breath sounds at the bases, diffuse wheezes, and coarse crackles. The white blood count was $13500 / \mathrm{mm}^{3}$ with a normal differential. Chest radiography showed increased interstitial markings and bilateral effusions. Milky pleural fluid was withdrawn on thoracentesis. The triglyceride level was $832 \mathrm{mg} / \mathrm{dl}$.

High resolution CT scanning showed small nodular densities in the para-aortic area and aortopulmonary window that were not present in 1990. A lymphangiogram with delayed upright views at 24 hours detected reflux of contrast into the left lung and fluid/fluid levels in the region of the thoracic duct (fig 1). The patient underwent a left anterior mediastinotomy. Numerous clusters of dilated lymphatics were seen in the mediastinum. Biopsy specimens revealed dilated proliferative lymphatic channels consistent with lymphangiomatosis (fig 2).

The patient required bilateral tube thoracostomy due to increasing effusions and underwent a thoracic duct ligation via a low right thoracotomy. The chylous drainage resolved postoperatively.

Two years later the patient is well. The pleural effusions have not reaccumulated. There is no evidence of lymphoedema and pulmonary function tests are normal. 


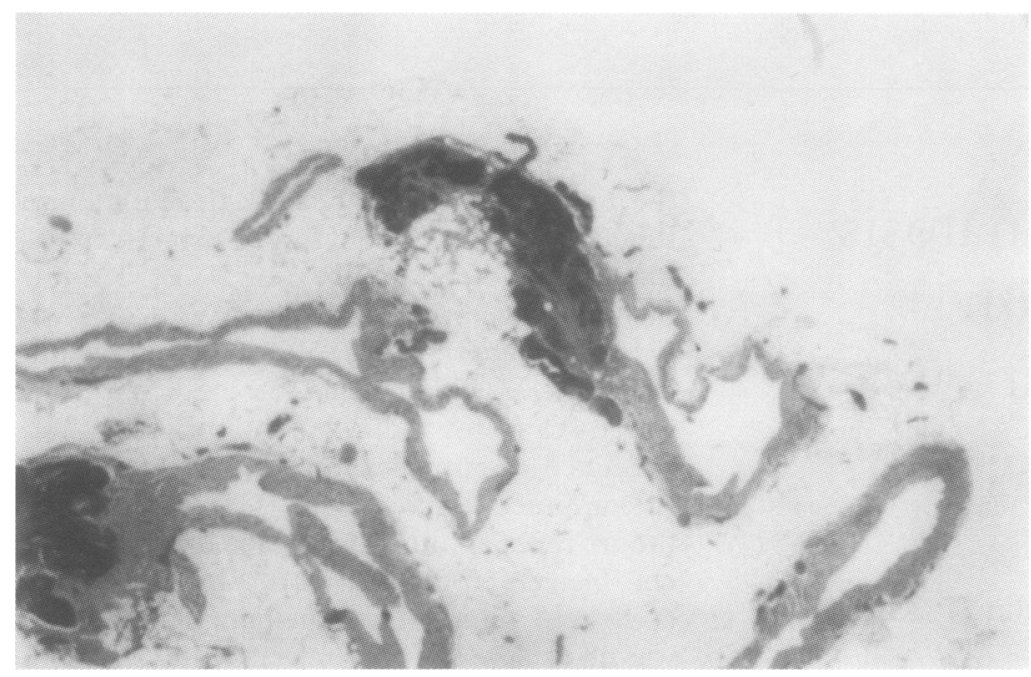

Figure 2 Mediastinal biopsy specimen showing dilated proliferative lymphatic channels consistent with lymphangiomatosis (original magnification $\times 10$, reduced to $62 \%$ in origination). bronchiectasis, bacterial infection, and plastic bronchitis, ${ }^{6}$ but chyloptysis is not routinely cited. In 1968 Maier $^{7}$ reviewed 17 cases of "chylous reflux into the lungs and pleurae" and found that two of six patients with chyloptysis had cast formation. Wetherill et al have also described a case in which chylous bronchial casts were expectorated. ${ }^{8}$ The sputum in that case was confirmed to be chylous by triglyceride analysis and the casts were noted to float in normal saline. An anatomical correlation between casts and a lymphatic abnormality was noted by Wiggins et $a l^{9}$ who reported a patient who expectorated casts for 23 years. The right middle lobe was eventually resected and dilated lymphatic vessels were noted in the hilum.

The diagnosis of lymphangiomatosis may be confirmed by lymphangiography with delayed upright views. ${ }^{10}$ Surgical resection may be difficult if lesions are diffuse. Other management options include observation, ${ }^{8}$ ligation of the thoracic duct, ${ }^{45}$ pleurodesis or parietal pleurectomy, ${ }^{7}$ low fat diet plus progesterone therapy, ${ }^{2}$ chemotherapy, and radiation.

Of these, thoracic duct ligation may prevent complications such as malnutrition, pulmonary fibrosis, and respiratory failure. ${ }^{458} \mathrm{~A}$ recent review of Gorham's syndrome complicated by chylothorax ${ }^{4}$ cited a survival rate of $72 \%$ in patients who underwent thoracic duct ligation compared with $36 \%$ without surgery.

1 Jett JR, Tazelaar HD, Keim LW, Ingrassia III TS. Plastic bronchitis: an old disease revisited. Mayo Clin Proc 1991; 66:305-11.

2 Swank, DW, Hepper, NGG, Folkert KE, Colby TV. Intrathoracic lymphangiomatosis mimicking lymphangioleiomyomatois in a young woman. Mayo Clin Proc 1989;64:1264-8.

3 Brown IR, Reiman HM, Rosenow EC, Gloviczi PM, Divertie MB. Intrathoracic lymphangioma. Mayo Clin Proc 1986;61:882-92

4 Tie MLH, Poland GA, Rosenow EC. Chylothorax in Gorham's syndrome. Chest 1994;105:208-13.

5 Sanders SS, Rosenow EC, Pichler JM, Gloviczki P, Brown LR. Chyloptysis (chylous sputum) due to thoracic lymphangiectasis with successful surgical correction. Arch Intern Med 1988;148:1465-6.

6 Fairshter RD, Riley CA, Hewlett RI. Large bronchial casts. Arch Intern Med 1979;139:522-5.

7 Maier HC. Chylous reflux in the lungs and pleura. Thorax 1968;23:281-96.

8 Wetherill SF, Davies AL, Mayock RL. Chyloptysis. Am $\mathcal{f}$ Med 1990;88:437-8.

9 Wiggins J, Sheffield E, Jeffery PK, Geddes DM, Corrin Wiggins J, Sheffield E, Jeffery PK, Geddes DM, Corrin
B. Bronchial casts associated with hilar lymphatic and B. Bronchial casts associated with hilar lymphatic and
pulmonary lymphoid abnormalities. Thorax 1989;44:2267 .

10 Miller DL, Fink IJ, Waldmann TA, Doppman JL. The upright film in lymphangiographic detection of lymphangiomatosis. $A \mathscr{Y} R$ 1985;145:847-8. 